\title{
Pierre Duhem and scientific truth: contextual, partial and real
}

\author{
FRANCISCO JAVIER LÓPEZ RUIZ
}

TDP Institute of Montreal

xavierlopezruiz@gmail.com

GEOFFREY WOOLLARD

TDP Institute of Montreal

geoffwoollard@gmail.com

\begin{abstract}
Mariano Artigas understood scientific truth as real, but at the same time contextual and partial. Artigas shared some research interests and a general outlook with Pierre Duhem. We summarize the evaluation of Duhem's thought by relevant authors and demonstrate how the way Artigas understood scientific truth in actual scientific research offers a suitable framework for capturing the realism towards which Duhem tended. This reading of Duhem runs counter to tendencies of the philosophy of science in Duhem's time which employed expressions that sometimes framed him as a conventionalist.
\end{abstract}

Keywords: Mariano Artigas; conventionalism; natural classification.

\section{Introduction}

Mariano Artigas dedicated his efforts to showing that scientific knowledge and knowledge through faith are not contradictory, but that there exists a fundamental harmony between them. He always stressed the relevance of philosophy as a form of human knowledge that is oriented towards 
issues that lie beyond physics and experimental science. Artigas stressed that experimental science has limits that make it incapable of proving or disproving the existence of God, although it does provide data for philosophical reflection that facilitates certain rational conclusions consistent with those proposed by faith.

Below is a characteristic articulation of Artigas's position regarding scientific truth:

Scientific truth exists, even if it is a truth that is contextual, partial and open to improvement.

[...] Scientific truth is contextual, because scientific statements have meaning only in well-defined theoretical contexts, which are always open to reinterpretation. Therefore, it is partial, and does not exhaust all that could be discovered. It is, however, real truth.

[...] Issues that can not be treated by the experimental method fall outside the realm of science. The scientific method requires that scientific statements be capable of being subjected to experimental control, which involves conducting experiments that, at least in principle, are repeatable. Therefore if something by its very nature cannot be subjected to experimental control, then it lies outside the scope of science. This is the case of the spiritual dimensions of man, and of metaphysical and religious issues. (Artigas 1992, 127-128)

These statements of Mariano Artigas are echoed in Pierre Duhem's work, who lived almost a century before Artigas. Duhem had a contextual and partial understanding of scientific truth-not a conventional understanding, but one proper to the scope of physical problems. This was expressed clearly in the introduction to his book on physical theory:

What is proposed here will be a simple logical analysis of the method by which physical science progresses. Perhaps some of our readers will want to extend the reflections that are described here to other sciences. Perhaps, too, they will want to draw consequences that go beyond the proper object of Logic. We carefully avoid one or the other extreme. We impose strict limits on our research, in order to explore our topic more deeply. (Duhem 1906a, xv) 
At the same time, both in his personal life and in his epistemological commentary, his status as a believer appears clearly. Duhem proposed a unitary theory of energetics, contrary to mechanism, and saw continuity between medieval and modern thinking. Some have seen this as proof of a faith-based position in favor of Catholicism. Already in Duhem's life, Abel Rey described Duhemian thought as the "scientific philosophy of a believer" in a tone that casts a certain discredit on the scientific value of his work. Duhem replied: "Certainly, I believe with all my soul the truths that God has revealed to us and that the Church teaches; I have never concealed my faith, which I hope will protect me, and I hope with all my heart never to be ashamed of it; in this sense it is fair to say that the physics I profess is the physics of a believer" (Duhem 1914, 414). Duhem goes on to explain how scientific work is performed with legitimate autonomy without foreign rules imported from faith or ideology.

Duhem's scientific thinking is certainly open to recognizing that reality is not limited to perceivable appearances. With the passage of time Duhem backed off from the initial sharp demarcation between physics and philosophy that he had made, admitting a progressive convergence and affirming the existence of an analogy between these two areas of knowledge. He acknowledged metaphysics as the domain of first principles and notions on which physics is based; but maintained that physics is free to formulate its models and representations apart from metaphysical interference-the only limitations being logical consistency and experimental control. These models and representations are not intended to confirm or deny the findings of philosophy, although neither are they arbitrary because the laws and representations of physics always tend, with scientific progress, to individuate and identify with the "natural classification" of laws that correspond to the intimate reality of things.

\section{The Traditional Position of Pierre Duhem}

It is not easy to situate this French physicist, historian and philosopher of science in the scientific and epistemological environment of the transition 
from the 19th to 20th century. He attempted to unify the different parts of physics into what he referred to as energetics (generalized thermodynamics). Based on this attempt he is frequently associated with Wilhelm Ostwald and other energists.

In the history of science, Pierre Duhem produced groundbreaking work in medieval science and defended the thesis that there is continuity between medieval and early modern science. It is traditional to frame him philosophically-epistemologically within the conventionalism and instrumentalism of his time, which sees in physical theory no more than a memory aid to classify data by means of symbolic representations. Among the motivations for this traditional view of Duhem's work we see three main reasons:

\subsection{Duhem and the French Conventionalists}

The first reason for the traditional framing of Duhem is the fact that he participated in the debates of his time surrounding the nature of scientific facts, laws and physical theories. Other figures in these debates included such contemporary French thinkers as Henri Poincaré and the philosophers Gaston Milhaud and Edouard Le Roy. Thus Duhem is associated with "French conventionalism". This occurs especially in neo-scholastic authors who severely criticize him. For instance, the neo-scholastic Eugène Vicaire saw positivism and skepticism in Duhem's separation between physics and metaphysics. Shortly after Duhem adopted a quasi-Thomist position: metaphysics is a real form of knowledge, more excellent than the physical, but separated from it because they have different objects and different methods. This is how Duhem came to be grouped with conventionalists.

Artigas, writing for a general audience, takes this up and explains that

The end of the dominance of classical physics coincided with the rise of conventionalist and instrumentalist doctrines in the late 19th and early 20th centuries. At that time, conventionalist and instrumentalist doctrines were associated mainly with Ernst Mach (1838-1916), Henri Poincaré (1854-1912) and Pierre Duhem (1861-1916). All three authors were first-rate scientists and reached similar conclusions from the analysis of mathematical physics, which 
was their specialty: concretely they claimed that by pure logic alone one can not prove the truth or falsity of scientific statements. Even though his philosophical background was very different [...] Duhem said that as science progresses, physical theories approach the representation of the order that actually exists in nature. Duhem affirmed the existence of a natural order that is reflected in objective scientific statements: he was a realist who also admitted the value of philosophy as knowledge of reality. (Artigas 1999, 73)

Here Artigas summarizes the traditional position, but emphasizes at the end the improper association of Pierre Duhem with conventionalism and instrumentalism. Artigas also introduces us to the second reason for the traditional position.

\subsection{Duhem's association with Ernst Mach}

The association of Mach and Duhem, mainly motivated by Mach's praise of Duhem's work, was interpreted as an indication that they held the same ideas. Artigas published an excellent article (Artigas 1991) underlining the fundamental difference between Mach and Duhem.

Mach's evolutionism and empiricism are not compatible with metaphysics. Mach influenced Moritz Schlick, the nominal leader of the Vienna Circle, which was publicly known as the Ernst Mach Society. However Duhem did not share any such presuppositions.

Duhem's well-known Catholic identity was no obstacle to scholarly interaction and collaboration with authors who lived by other worldviews. Mach wrote the preface to Duhem's The Aim and Structure of Physical Theory in the 1908 German-language edition. In his own writings, Mach wrote how Duhem's work shed light on the relationship between ordinary and scientific knowledge. Mach considered parts of Duhem's writing as complementing his.

What was their common ground? Duhem taught that a truly wise understanding comes from situating knowledge in its historical context and as part of a story, rather than treating mathematical abstractions as concrete entities. Mach considered this his position as well-a stable stance maintained over the final three decades of his life. Mach and Duhem also 
held a common position on the interpretation of the experimentum crucis: a "magic bullet experiment" that provides closure to a scientific question in one fell swoop. Instead they maintained that experiments pertain to a collection of hypotheses rather than just one isolated hypothesis.

Even though Mach and Duhem shared much common ground, they diverged in their global vision of what science is. Mach's outlook on science had a survival-of-the-fittest character: pragmatic rather than metaphysical. Duhem was convinced that the natural order really exists and that we approach it through increased scientific characterization. Duhem was open to an order that transcends physics, chemistry, biology, etc.-indeed all of nature.

But their divergent conclusions should come as no surprise. They set out from different starting points. Duhem started from the logical analysis of physical theories, and considered scientific thinking as just one aspect of human rationality. Science self-limits the arena of rationality it operates in. Mach started from a psychological axiom: sensations are the only real thing. And so he rejected any knowledge he could not fit into his empirical system.

Both Mach and Duhem appealed to history to support their theories. Mach looked at history through the lens of certain key scientists. Duhem was interested in the historical origins of physics. As he delved deeper and deeper he was led all the way back to original unedited manuscripts from the middle ages. He collected ancient writings and published his commentary in ten massive volumes. Amid the wealth of historical details and interconnections, a theme emerges: a Christian worldview underlies the birth of modern science. His extensive work led him to the conclusion that science, philosophy, and Christianity are consistent with one another.

Duhem's work in this area laid a solid foundation for the history of science and his findings continue to be a point of reference for future research to this day.

Mach's instrumentalism has no place for deep reflections about truth. Duhem's instrumentalism lacks this positivist flavour, and is open to deep reflections about truth.

Duhem analyzed physical theories from a logical point of view and did not support naive realism. Unlike Mach, Duhem's conclusions do not spring 
from an anti-metaphysical attitude. We can see that Duhem is open to metaphysics by his conviction that in science we are gradually approaching the real natural order.

Duhem's 'positivism' differs to such an extent from the common meaning of this term that Artigas avoids it when describing Duhem. Duhem said that scientific laws are constructive, symbolic and approximate. The order of these laws approaches the real order in nature.

\subsection{A Limited View of Duhem's work}

Duhem wrote a lot, and one needs to read widely in order to ascertain what he really meant. The third reason for the traditional reading of Duhem is that it is derived only from a partial analysis of his work, limited practically to his book The Aim and Structure of Physical Theory and to an indirect knowledge of Duhem through the works of Vienna Circle members, Popper, and especially Quine (cf. the "Duhem-Quine thesis") as can be easily verified in the important collection of essays edited by Harding (Harding 1976).

Roger Ariew, the author of the Stanford Encyclopedia of Philosophy entry on Duhem, offers a good summary of this third reason:

Duhem's work was important for members of the Vienna Circle, including Otto Neurath and Philipp Frank, as it had been for Ernst Mach [...] The Duhem thesis surfaced fully in Anglo-American philosophy in the 1950s through the work of W. V. O. Quine. In Quine's “Two Dogmas of Empiricism,” the second dogma is reductionism, the belief that "each meaningful statement is equivalent to some construct upon terms which refer to immediate experience" [...] Against this dogma Quine suggests that "our statements about the external world face the tribunal of sense experience not individually, but only as a corporate body", and, in a footnote of the reprinted article in his collected essays, From a Logical Point of View, says that the doctrine was well argued by Pierre Duhem.

[...] Duhem's formulation of his non-falsifiability thesis is that "if the predicted phenomenon is not produced, not only is the questioned proposition put into doubt, but also the whole theoretical scaffolding used by the physicist" [...] He refers to two possible ways of proceeding when an experiment contradicts the consequences of a theory: a timid scientist might wish to safeguard 
certain fundamental hypotheses and attempt to complicate matters by invoking various cases of error and multiplying the corrections, while a bolder scientist can resolve to change some of the essential suppositions supporting the entire system [...] Moreover, Duhem does not argue directly for the non-falsifiability thesis. He seems to regard it as an obvious corollary of another thesis, which could be called the non-separability thesis. (Ariew, 2014)

We should keep in mind that Duhem's methodology establishes a precise structure for the development of physical theory: experimentation and physical laws, choice of hypotheses, logical-mathematical elaboration of physical theory, and confrontation of the theory's implications with experience. The origin of the construction of a theory must be methodologically abstract and take into account only the conditions imposed by logic. But, once the theoretical edifice is completed, the inevitable moment arrives of its confrontation with the facts and experimental laws. The comparison of the results with experience acquires particular characteristics in Duhem's thought, which have been consolidated in the previously cited holistic thesis: we cannot subject isolated hypotheses to experimental control. One must compare experimental data with the entire set of assumptions that come from the physical theory. The experimental test might have implications for any hypothesis that the theory relies on.

David J. Stump gives a good summary of the traditional image of Pierre Duhem and proposes a way to rectify it.

A negative result only casts doubt on the whole, not on a specific theory. Duhem thus raises a central issue in the philosophy of science: How are theories chosen when empirical evidence is underdetermined? However, Duhem thinks that we can justifiably adopt and refute scientific theories, given that we are not limited to a deductive method. We have an intuitive reasoning ability, which Duhem terms 'good sense', that allows scientists, like judges in a legal setting, to be able to weigh evidence and to be fair and impartial. (Stump 2007, 149-150)

Stump's central thesis is that “moral virtues are at the centre of Duhem's philosophy of science, a point that is often overlooked or slighted as unimportant by those who follow his epistemology” (Stump 2011, 13). Stump 
points out the ethical dimension of 'good sense' and shows how Duhem connected the intellectual and moral virtues of the scientist with their actual creative scientific work (Stump 2007).

This line of thinking is certainly interesting, but has a slightly Kantian flavor. In contrast, Milena Ivanova is not convinced by Stump's "ethical" interpretation of "good sense", and points to the need for intellectual virtues:

By stressing the importance of intellectual virtues in theory choice, Duhem's complex view of rationality helps us recognize that judgment is part of scientific practice. Duhem realized that scientific practice cannot be described as the following of algorithmic rules. We have to consider the involvement of virtues and values in theory choice, but this need not amount to a denial of rationality. By invoking the concept of good sense, Duhem accounted for rationality in science and avoided relativism since he provided some general guidance to scientists faced with the problem of theory choice. (Ivanova 2010, 64)

\section{Approaches to Duhem}

Stanley Jaki reacted strongly to the traditional reading of Duhem (Jaki 1987). He provided great insight into Duhem's personal life (Jaki 1990). He opened a new approach, but linked his findings up with his own writings on science. Following in Jaki's footsteps we start with Duhem and focus on three aspects that paint a different picture than the traditional one described above.

\subsection{Duhem's Scientific Career (Roberto Maiocchi)}

Despite Duhem's monumental work as a historian of science and the importance of his publications in epistemology and the philosophy of science, Pierre Duhem always wanted to be recognized primarily as a physicist. In the field of physics his contributions are important to the thermodynamics of irreversible phenomena. His writings on thermodynamic potential and chemical physics are well-known, and the Gibbs-Duhem and Duhem-Margules equations, as well as the Clasius-Duhem inequality, have become common heritage in thermodynamics. 
Roberto Maiocchi kept in mind Duhem's desire to be primarily recognized as a physicist (Maiocchi 1985). Maiocchi sets out to reconstruct the coherence of Duhem's thought. Maiocchi focuses on Duhem's scientific work, his criticism of mechanism and his view of continuity in the progress of physics. He emphasizes Duhem's opposition to English physics which was replete with numerous mechanical models each at odds with the other and with simple tools to address specific questions.

Maiocchi shows that The Aim and Structure of Physical Theory argues against radical conventionalism (Maiocchi 1990). He adeptly explains that Duhem cannot be a conventionalist, because conventionalism was a result of the crisis of classical physics, while the physics of Duhem's era predates that crisis. Moreover, Duhem is a realist and fought against the instrumentalism of English physics.

How did Duhem the conventionalist never, not even once, use the term 'convention'. And in all the fundamental epistemological problems concerning the notions of experience, law, theory, etc., how did he stubbornly argue with those who should be his allies, Mach, Poincare and Le Roy? [...] what kind of instrumentalist is Duhem to wage such a fierce battle, epic in the history of science, against English physics, accusing it of being a form of instrumentalism, and because of its very instrumentalism, of being unacceptable? Is he not a strange phenomenalist, then, and a somewhat degenerate student of Mach, who writes a book (The Aim and Structure of Physical Theory) to celebrate the role of hypotheses, designed as 'free creations', and urges physicists to overlook experience in the theory-building process? [...] How is it that in the book that came to be considered the most focused and systematic attack on the confidence in the cognitive value of science typical of positivismhow is it that this book actually systematically, obsessively, reminds us that science proceeds toward a 'natural classification', towards the construction of an ordering of nature that reflects, albeit always imperfectly and open to improvement, an objective order? (Maiocchi 1985, 3-4)

Duhem aimed to formulate a physical theory that would not be at the mercy of conformity. He proposed a highly mathematized physics relying on the importance of theory, but warned that a physical theory is not a metaphysical 
explanation of reality but rather an abstract representation of experimental laws which tends to provide a natural classification of such laws. The completion of Duhem's physical theory would not end with the full development of the theory, but leads to an invitation to connect with Aristotle, because Duhem spoke of an analogy between energetics and Aristotelian physics.

Maiocchi stresses Duhem's search for rigor and consistency. From this perspective of unity and clarity, the natural classification that Duhem proposed makes sense, while an instrumentalist perspective of Duhem does not. Stoffel (Stoffel 2002, 92) emphasizes how Maiocchi (Maiocchi 1985, 206, 223) stresses the error of Lakatos's reading of Duhem, who spoke of him as an "incoherent revolutionary". Duhem was methodical and consistent; if we have the impression he was not consistent, that may be the result of having misinterpreted him as a conventionalist. Duhem is far from being revolutionary. He is a rather clear-cut conservative who devotes his energies to demonstrating the central role of historical continuity in physics. Thus, to put things in familiar philosophy of science language, Lakatos' hypothesis of Duhem is falsified.

From his early work in the philosophy of science, Duhem makes it clear that he conceived physics as a science endowed with real cognitive value, leading to a natural classification of experimental laws. Duhem highlights the importance of a theory's consistency (rigor, beauty, etc.). What do these epithets mean? If science tends to truth, then it should strive for consistency. If science renounces consistency, it renounces truth.

Therefore, Duhem is not a positivist from an ontological perspective. He strongly affirms the existence of metaphysics: "The belief in a transcendent order to physics is the only raison d'etre of physical theory" (Duhem 1914, 509). Moreover, for him physics is methodologically autonomous from metaphysics. Physics only seeks to "save appearances." The goal of physical theory is to approximate more and more the natural classification of experimental laws, showing a logical coordination that is an image and reflection of a cosmic order that goes beyond the object of physics.

Anthony Rizzi shares some common ground with Maiocchi's perspective. He contrasts the science before science (philosophy/metaphysics) with 
modern science. The science before science thinks analogically. Multiple layers of meaning exist in a mental framework that is not predefined within a closed system of rules. "Philosophy requires one to stop and stare at reality; it requires receptiveness to reality. For to access truth, one must conform oneself to reality. It needs a certain stillness and patience with what appears to be obvious, but is more than just obvious, it's profound" (Rizzi 2004, 355). He quotes Duhem's work to give us perspective on the hidden gems in ancient thought:

If we rid the physics of Aristotle and of Scholasticism of the outworn and demoded scientific clothing covering it and if we bring out in its vigorous and harmonious nakedness the living flesh of this cosmology, we would be struck by its resemblance to our modern physical theory: we recognize in these two doctrines two pictures of the same ontological order, distinct because they are each taken from a different point of view, but in no way discordant. (Rizzi 2004, 355)

Paul Needham has also published a good number of articles on Duhem's scientific work, emphasizing his “moderate realism” (Needham 2011, 7). Needham thinks this moderate realism is the key to understanding Duhem's position regarding theory as representation and not as explanation. Duhem

took explanation very seriously. This is particularly clear in Duhem's argument against atomism. Philosophers have given little attention to the detailed arguments of the anti-atomists and been too quick to ascribe the resistance to atomism in the nineteenth century as due to positivist scruples about what cannot be directly observed. There is certainly no trace of any such appeal to observation in Duhem's case against atomism. (Needham 2011, 7)

In a prior article, Needham shows that it is quite clear that what Duhem means by "explanation" in atomism is appeal to a priori theorising about the ultimate reality underlying the deliverances of scientific theory (Needham 1998).

Needham summarizes Duhem's moderate realism:

Thermodynamics explains phenomena beyond the scope of mechanics, and in Duhem's vision incorporates the old mechanics in a broader theory. But he 
had no thought that physics had thereby been completed nor that any present researcher could meaningfully delimit final complete physics in any non-trivial way. Nevertheless, unification, not by reduction to preconceived ideas but by expansion and integration into a general theory without internal contradictions, is the goal of science, which he called a natural classification. (Needham 2011, 12)

\subsection{Duhem's History of Science (Anastasios Brenner)}

Following the trail blazed by P. Brouzeng (Brouzeng 1987), we come to another important treatment of the subject at hand offered by Anastasios Brenner. Brenner distinguishes three readings of Duhem: traditional, contextual and his own historical reading. The traditional reading begins in Duhem's own time and continues into the neo-positivist period. The contextual reading dates from the 1980s and 1990s and corresponds to the personal element emphasized by Jaki and the scientific context described by Maiocchi and Artigas, among others. Brenner argues for the importance of the role of history in Duhem's thought. He explains that

a historical approach to philosophy of science can be pursued in many ways, and indeed has given rise to a variety of styles of research. One direction consists in grounding philosophy of science on the history of science. Duhem's work offers in this respect a noteworthy example. In The Aim and Structure of Physical Theory, 'logical analysis' was complemented by recourse to historical study, both entering into a detailed and complex view of the nature and goal of theoretical physics. (Brenner 2011, 2)

Brenner notes that Duhem includes the history of physics in his very first publications (and more intensely after 1900) to support his other work. With the publication of Les origines de la statique, Duhem embarks on a journey aimed at writing history in a more serious manner employing genuine historical methods. One can speak of a true conversion of Duhem to the historical sciences. Behind the scenes, however, we can sense how the history of science is the key to an epistemological history, even though he does not call it that. 
Brenner explains how historical discoveries come to modify the epistemological conceptions of Duhem, which evolved from inductivism to the recognition of the crucial importance of theory (Brenner 1990, 19, 24, 38). Keeping firm in mind the objective of "saving appearances", Duhem originally employed an argument close to inductivism until, with the help of historical research, he arrived at the exact formulation of his holism thesis. Later historical investigation brought Duhem to improve his explanation of the methodology of physics and to develop his epistemological position. On the one hand, strictly methodological positivism-as Brenner calls it-is the hallmark of materialistic scientism. This scientism bases anti-metaphysical worldviews upon the results of science. On the other hand, Duhem also admits that scientific autonomy is necessary in the logical-mathematical development of physical theory. He also introduces the notion of good sense [bons sens] (the indirect intervention of common sense, philosophical sense, ethics, etc. during the creative process) and of historical guidance to show the way forward in the creative process of physical theory.

The historical context of each scientist has a great influence on his work and decisions: the history of science not only explains the choice of principles, but also represents our perspective for all scientific activity, physics in particular. The historical approach to the study of science will come to be characteristic of the post-positivism represented by Kuhn, Lakatos, Feyerabend and Laudan to those after Duhem. The big difference between them is that Duhem was a great supporter of historical continuity. The guiding criterion that he adopted was the maximum preservation of the scientific heritage of those who have come before us. He based this on the fact that "great revolutions" in the lives of scientists are exceptional and the norm is continuity, working to enrich theory and completing established theory. Among the most notable historical results is undoubtedly the discovery of the importance of medieval science, as a result of his work on the origins of statics. This discovery gave strength to his thesis of "historical continuity", a key element of his epistemology. In any case, Duhem pioneered the study of medieval science. Authors such as Koyré, Dijksterhuis and Maier continued on his work. 


\subsection{Duhem's Apologetics (Jean-François Stoffel)}

Duhem established a clear distinction between the subject areas of physics and philosophy. His exact motivations are a matter of debate. In this section we will clarify what role apologetical motivations had in Duhem's work and make a connection between his style and Pascal's.

R. N. D. Martin was the first to highlight the apologetic dimension of Duhem's work, speaking of a religious "hidden agenda" and emphasizing the influence of Blaise Pascal in Duhem's thought (Martin 1991). Artigas adds that "the work of Duhem on medieval science may have been motivated by religious concerns, including apologetic ones. But, apart from that legitimate goal, his work has contributed decisively to demonstrating the falsity of positivism. Duhem shows that Christianity played an important role in the progressive development of the ideas that led to the birth of modern science" (Artigas, 1991, 115).

Duhem used the results of this work for apologetic goals, in order to try to restore the value of the scientific culture of medieval Christianity and also to introduce the idea of divine Providence governing the world and guiding the progress and development of the sciences through history. For example, what he wrote in Les origines de la statique is significant:

Even more than the growth of a living being, the evolution of statics is the manifestation of the influence of a guiding idea. Within the complex data of this evolution, we can see the continuous action of a divine wisdom which foresees the ideal form towards which science must tend and we can sense the presence of a Power which causes our efforts to converge towards this goal. In a word, we recognize here the work of Providence. (Duhem 1906b, 289-290; translated in Deltete 2011,23)

Deltete writes about this motivation that

Duhem sought to separate physics from metaphysics, but he also tried to bring them into contact. The key to this rapprochement was the concept of natural classification, the idea that physical theory tends to a classification of physical and chemical phenomena which mirrors the ontological order of nature. This is 
one of a pair of tensions in Duhem's work. A second is that while his 'scientific philosophy' offered arguments for natural classification that did not depend on religion, Duhem could not resist bringing Providence back in as the ultimate explanation for the approach of physical theory to natural classification. (Deltete 2011, 24)

Jean-François Stoffel defines Duhemian phenomenalism as the separation that Duhem makes between physical theory and metaphysical explanations. Stoffel explains that Duhem's phenomenalism is neither anti-metaphysical nor skeptical, but has a regulating role (Stoffel 2002, 359) because it is limited to circumscribing physics and metaphysics, determining the respective scope of each branch of knowledge.

What were Duhem's motivations? Stoffel describes Duhem's apologetics: "Duhem, a Catholic, established a real apologetic battle plan, defensive in physics and offensive in history. It was destined to counteract, in the short term, the idea that scientific spirit and religious spirit are incompatible" (Stoffel 2008, 112). Duhem maintained a separation between physics and metaphysics that denied the right of physical theories to intervene in the metaphysics debate, either in favor of one side or the other. Stoffel ask an interesting question: "How can we understand that our author could oppose such a rejection to the urgent appeal of other Christians? At first he developed a defensive apologetics in the scientific field. And then he proposed an offensive apologetics? How can we explain this switch? The influence of Pascal, combined with several events of the early 1890s, allows us to account for this attitude" (Stoffel 2007, 296-297).

Stoffel concludes that Duhem

is in reality, and before any other choice, a Pascalian. Not only to the extent that he was inspired in his personal life and in his work by the author of Les pensées, but more fundamentally, to the extent that his doctrine may be considered as an updating and commentary by a scientist-philosopher of the 19th century of what Pascal had once suggested. (Stoffel 2007, 301)

In La science allemande and Quelques réflexions sur la science allemande Duhem explicitly takes up Pascal's epistemology. 
Duhem's phenomenalism serves to support an image of science that is unified, continuous and consensual (Stoffel 2002, 359-360). Moreover, Duhem's apologetics is supported by his phenomenalism. On one hand, his phenomenalism delimits the domains of physics and metaphysics so that physics cannot be mistaken for metaphysics and replace philosophy, morality and religion, which is what happens with scientism. On the other hand, with phenomenalist physics and metaphysical realism being located on different planes, science is prevented from attacking religion and religion from interfering with science. This separation "on paper" is connected in the life of a scientist "in practice", as they use everything at their disposal to creatively do science.

\section{The Continuing Validity of Mariano Artigas' Principles}

Each area of the sciences, even the most mathematized ones, reaches true causal explanations (they explain the causes of the tides, rain, diseases, the properties of chemicals, etc.). Only at certain levels and in certain stages of the scientific process is physics limited to a descriptive phase, appealing to hypotheses that are hard to test. But still, these hypotheses are "alleged" causes. Duhem's rejection of physical explanation happened in a historical context, and therefore it cannot be absolutized: Duhem is aware that mechanistic explanations of classical physics are in reality reversible and creative ways of measuring phenomena. Physics cannot be expected to offer a perfect reflection of the physical world.

We obtain, as Duhem has put it, better approximations to a natural order which can also be the object of philosophical reflection.

In fact, philosophy is needed if we desire to find a connection between experimental science and human rationality. [...] Duhem's attitude was exemplary, as he restricted himself to the logical analysis of physico-mathematical theories, without extrapolations which are so tempting for the philosopher of science. (Artigas 1987, 96) 
Duhem claimed that physics does not seek to "explain" reality, one reason being obtaining general consensus in physical theory. Indeed, Artigas explains that

It is not that physical theories have no connection with reality: Duhem explicitly states, on the contrary, that the more a physical theory is perfected, the more actual order becomes apparent, which is a reflection of an underlying ontological order. What Duhem argues is that the method [our emphasis] according to which theories are constructed must be free from metaphysical elements, and only thus can we ensure the autonomy of physical science with respect to metaphysics, and thus reach universal consensus. (Artigas 1979, 23-24)

At the same time, Artigas explains very well why for Duhem the mathematical mind (esprit géométrique) is not enough to explain how science actually works. An intuitive mind (esprit de finesse) and reasons of the heart are also needed.

Indeed, the desire to base intersubjectivity on a strictly logical basis leads us to demand that experimental science give us perfectly 'logical demonstrations', in other words, that demonstrations can be formulated by arguments that include only logical connections. [...] Nevertheless, the analysis of actual scientific activity shows unequivocally that, in fact, we use various kinds of stipulations, which can not be logically reduced to a definitive rock-solid basis. (Artigas 1989, 242)

We are not required to equate "logical demonstrability" with "scientific intersubjectivity", as if science had to be "understood" by a robot or a computer.

In real science, we use stipulations from the outset [...] that are recognized as 'good reasons' by some researchers and come to enjoy general acceptance in such a way that once accepted, such reasons appear as something natural, as if they could be definitively demonstrated, when in reality they cannot, as historical experience has shown. Very often these generally accepted stipulations are given new perspectives based on 'better' reasons. (Artigas 1989, 245, 252)

Stoffel thinks that Duhem's phenomenalist approach, both in terms of science and apologetics, is a form of contextual and methodological phe- 
nomenalism; i.e. it positions physical theory with respect to metaphysics. Artigas goes much further, arguing that what is contextual is the truth of physical theory itself. In our view, Artigas' approach allows a less problematic understanding of Duhemian phenomenalism.

It is legitimate to admit the existence of a scientific truth that is contextual, partial and real. Empirical conformity is a necessary condition or minimal requirement that scientific constructs have to meet, but does not exhaust the significance of scientific constructs [...] The abstract and formal level reached by present-day physics would greatly satisfy Duhem, since it coincides with the direction of his scientific work and his epistemological ideas. Nevertheless, it is possible to show that, through highly abstract and sophisticated constructions, we describe reality and in fact know it better. Although Duhem's work only aims in this direction, it corresponds with his essential ideas. (Artigas 1991, 111-112)

Duhem seeks a logical order of theoretical constructs that is the "reflection of an ontological order", and the more physical theory progresses, the more he is convinced that "the relations established between observational data correspond to relationships between things":

In experimental science we can reach a truth that is 'contextual' and therefore 'partial', but at the same time is 'real' truth in the sense that the statements correspond to reality. Scientific truth is not partial in the sense that it is limited to superficial aspects of reality. Whoever affirms the contrary, wanting to leave more room to metaphysical or theological discourse, would actually weaken the capacity of human reason and would have difficulty laying claim to a rational basis for metaphysics and theology. (Artigas 1995, 102-103)

It is important that we not forget Duhem's conviction about the progressive and continuous advancement of physics. This progress occurs not so much through revolutionary changes that destroy a previous theory as through renewals that require reformulating old theories, which tend to stay as particular cases of new theories, in a narrower context than previously thought.

To advance physical theory, Duhem says there is no strictly logical criteria that allows us to know whether we must reject a hypothesis. At the same 
time he admits that there are other reasons, that (without excluding logic) direct the choice of hypothesis or help us to know what should be rejected or at least modified. Duhem calls these reasons common sense: They are "reasons of the heart", which play a role in justifying the choice of hypotheses and in verifying them. One could say that progress goes beyond the method of physics, it also exceeds the historical study of scientific developments, and involves a notion of progress that might be called metaphysical.

We find that, after a century, the development of physics shows that Duhem's ideal of a unified theory-the physical theory that coincides with the terminology of his time-is still not able to keep pace with experimental breakthroughs. Various theories have arisen that always share common ground and often share complementary results. Yet these theories always fall short of that long-sought-after unified theory, because they refer to different contexts and are increasingly differentiated. "Scientific activity is concerned with the search for truth. More than that, scientific activity is properly understood when placed in relation with its distinctive scientific objectivity and with the corresponding contextual truth" (Artigas 1989, 346-347).

\section{Conclusion}

In some way, we do not have an answer to the complexity of current scientific progress from Duhem's perspective, but we think he sets us off in the right direction. Presenting scientific truth as "contextual knowledge" offers an approach that can give a healthy outlook of Duhemian holism, reshaping things differently than Quine. It seems to us that the notion of "contextual knowledge" complements Duhem's perspective and is a potentially fruitful area of investigation for future research.

Duhem perpetuated the entire realist tradition in his philosophical thought. Duhem sought the cognitive roots from which scientific development grew, and came to the conclusion that they are to be found in the human faculty of intelligence. Both faith and common sense, along with intuition, are at play in the scientific process. Nor can emotions and feelings be excluded from that process. Given the physicist's freedom to choose 
hypotheses and to build physical theory, Duhem suggested that scientists allow themselves to also be guided by "reasons of the heart" and by bon sens, in other words, by philosophical and common-sense arguments. He sets, however, some conditions for the epistemology of physics in so far as it is a discipline of a philosophical character. These conditions sketch out an epistemology that is both descriptive and non-normative. It seems clear that Duhem wishes to convey that he is not authorized-as a scientist-to authoritatively establish these standards; however he suggests that the historical facts of the development of physics can be used to corroborate the claims of a scientific epistemology.

The philosophical implications of theories have given rise to interesting discussions that allow respect for the analogy that Duhem proposed. Paraphrasing Duhem, we could say that as each physical theory "progresses" and is perfected the stronger the conviction becomes that that logical order reflects an ontological order. This is precisely one of the reasons why we can say that science "progresses": because it increases our conviction that its relations adequately represent reality. It seems to the authors that "progress of science" is best understood in a realist sense if one accepts that "scientific truth is contextual" as Artigas has proposed (i.e. true given a material context framing every physical problem and also a historical context of mankind's progress). At the same time, this view leads us to recognize the great merit of pioneers like Pierre Duhem. With Artigas we affirm that scientific truth is not total and absolute, but rather contextual, partial and relative to each particular physical problem. But at the same time scientific truth is solid and endows physical science with a peculiar consistency that helps us better understand both the nature and scope of physical science.

\section{References}

Note: The quotations marked with an * are translated by the authors.

Ariew, R. 2014. “Pierre Duhem”, The Stanford Encyclopedia of Philosophy (Fall 2014 Edition), edited by Edward N. Zalta, URL $=<$ http://plato.stanford.edu/archives/ fall2014/entries/duhem/>. 
Artigas, M. 1979. “La confiabilidad de la ciencia y su impacto filosófico.” PhD diss., Universidad de Barcelona.*

-. 1987. "Pierre Duhem: The Philosophical Meaning of Two Historical Theses." Epistemologia 10:89-97.

-. 1989. Filosofía de la ciencia experimental. Pamplona: Eunsa.*

-. 1991. "E. Mach y P. Duhem: El significado filosófico de la historia de la ciencia.”

In S. L. Jaki, C. Sánchez del Río, J. A. Janik, J. A. Gonzalo, y M. Artigas. Física y religión en perspectiva, 99-119. Madrid: Rialp.*

-. 1992. “Los límites del lenguaje científico.” In Veinte claves para la nueva era, edited

by J. M. Ortiz, 113-132. Madrid: Rialp.*

-. 1995. "Scienza e verità parziale.” In La verità scientifica, edited by R. Martínez.

Roma: Armando Editore.*

-. 1999. Filosofía de la Ciencia. Pamplona: EUNSA.*

Brenner, A. 1990. Duhem: Science, réalité et apparence. Paris: Vrin.

-. 2011. "The relation between history and philosophy", 1-7. In New perspectives on

Pierre Duhem's The aim and structure of physical theory. Metascience 20/1:1-25.

Brouzeng, P. 1987. Duhem: science et providence 1861-1916. Paris: Belin.

Deltete, R. 2011. “Homme de science, homme de foi: Pierre Duhem on science and religion”, 18-24. In New perspectives on Pierre Duhem's The aim and structure of physical theory. Metascience 20/1:1-25.

Duhem, P. 1906a. La théorie physique, son objet, sa structure. Paris: Chevalier et Rivière.* Réédition 1914. Paris: Chevalier et Rivière.*

-. 1906b. Les origines de la statique II. Paris: Hermann.

Harding, S., coord. 1976. Can Theories Be Refuted?: Essays on the Duhem-Quine Thesis. Dordrecht, Holland: D. Reidel Publishing Company.

Ivanova, M. 2010. “Pierre Duhem's good sense as a guide to theory choice.” Studies in History and Philosophy of Science 41:58-64.

Jaki, S. L. 1987. Uneasy Genius: The Life and Work of Pierre Duhem. Dordrecht: Martinus Nijhoff.

-. 1990. Pierre Duhem, homme de science et de foi. Paris: éditions Beauchesne.

Maiocchi, R. 1985. Chimica e filosofia: scienza, epistemologia, storia e religione nell'opera di Pierre Duhem. Florencia: La Nuova Italia.*

-. 1990. "Pierre Duhem's 'The aim and structure of physical theory’: A book against conventionalism.” Synthèse 83/3:385-400.

Martin, R. N. D. 1991. Pierre Duhem: philosophy and history in the work of a believing physicist. La Salle, IL: Open Court Publishing.

Needham, P. 1998. “Duhem's Physicalism.” Studies in History and Philosophy of Science 29:33-62. 
-. 2011. “Duhem's moderate realism”, 7-12. In New perspectives on Pierre Duhem's The aim and structure of physical theory. Metascience 20/1:1-25.

Rizzi, A. 2004. The science before science: A guide to thinking in the 21st century. Baton Rouge, LA: Institute for Advanced Physics Press.

Stoffel, J.-F. 2002. Le Phénoménalisme Problématique de Pierre Duhem. Brussels: Classe des Lettres, Académie Royale de Belgique.*

-. 2007. "Pierre Duhem: Un savant-philosophe dans le sillage de Blaise Pascal.” Revista Portuguesa de Filosofia 63:275-307.*

-. 2008. "Pierre Duhem avait-il 'quelque théologien derrière lui' lors de l'élaboration de son articulation de la physique et de la métaphysique? Le cas de Maurice Blondel.” Recherches philosophiques 4:89-116.*

Stump, D. J. 2007. “Pierre Duhem's virtue epistemology.” Studies in History and Philosophy of Science 38:149-159.

-. 2011. “The scientist as impartial judge: moral values in Duhem's philosophy of science”, 12-18. In New perspectives on Pierre Duhem's The aim and structure of physical theory. Metascience 20/1:1-25. 